\title{
EDUCACIÓN
}

\section{Diseño y creación de la Unidad General de Orientación Educativa y Psicopedagógica en el Departamento Central de Paraguay}

\author{
Hugo Daniel Yahari ${ }^{1}$
}

\begin{abstract}
Resumen
Introducción: Paraguay actualmente se encuentra en un proceso de transición respecto a la inclusión en el sistema educativo de personas con necesidades educativas de apoyo y la implementación efectiva de la normativa vigente, la Ley N 5136/2013 "De la Educación Inclusiva". Esta propuesta plantea la creación del servicio de Orientación Educativa en Paraguay a la que se pretende denominar Unidad General de Orientación Educativa y Psicopedagógica (UGOEP). Esta iniciativa se gesta como mecanismo de apoyo a la tarea docente, y estrategia para efectivizar la labor en el aula, conscientes de que la formación docente inicial no contempla formación especializada para el diagnóstico e intervención ante alguna situación que así lo ameriten, no obstante, con el apoyo que la UGOEP les brinde podrán detectar situaciones de Alumnos con Necesidades especificas de Apoyo Educativo (ANEAE) en el aula, y poder así derivarlos para su intervención efectiva. La UGOEP toma como antecedente para su diseño la experiencia del Reino de España a través de los Equipos de Orientación Educativa y Psicopedagógica (EOEP) los cuales constituyen un elemento trascendental de apoyo a los centros educativos.
\end{abstract}

Objetivo: Diseñar una propuesta de innovación para la educación paraguaya del sector público de la Educación Escolar Básica de los 1ํy 2읃clos.

Material y Método: La metodología utilizada ha sido la revisión de fuentes primarias y secundarias tales como: Informes, normativas nacionales e internacionales, sistematización de experiencias del Reino de España, resoluciones emanadas desde el ente rector de la educación en Paraguay y España.

Resultados: Una Propuesta de Innovación: La orientación educativa debe entenderse como una labor compleja y a su vez importante en especial en los centros de formación donde se ofrecen los servicios de Educación Inicial y Escolar Básica, lo es por su carácter diverso y complejo de elementos que componen

1. Universidad Complutense de Madrid (UCM). Facultad de Formación del Profesorado en Educación.

Trabajo realizado en el marco del Máster Internacional Especializado del Profesorado con Énfasis en Orientación Educativa.

E-mail: shakekuku@gmail.com

DOI: $10.26885 /$ rcei.foro.2018.56 
su esencia de trabajo; por lo cual requiere de destrezas y conocimientos que se desarrollan más en la práctica que durante la formación profesional o académica de los responsables de poner en marcha al Equipo como tal, diferentes perfiles son los que se contemplan en el Capítulo IV "Del Equipo Técnico" de la Ley № 5136/13 "De Educación Inclusiva", entre ellos Psicólogos, Psicopedagogos, Fonoaudiólogos, Trabajador Social, Terapista Ocupacional y Especialistas por Discapacidad, esta pluralidad multidisciplinar de profesionales expresa la riqueza de los Equipos Técnicos, en la Tabla 2 se presenta un cuadro comparativo entre los EOEPs (España) y los Equipos Técnicos (Paraguay), contemplados en la normativa vigente cuyas líneas son base de la presente propuesta de creación e implantación de la Unidad General de Orientación Educativa y Psicopedagógica en el Departamento Central de Paraguay.

Conclusiones: La propuesta es sólo un volcado de ideas debatidas y consensuadas por el autor, cuyo deseo es el de trasladar la experiencia de contar con un Equipo que apoye la tarea docente y pueda dar marcha a lo establecido en las normativas vigentes en la Republica del Paraguay respecto a la Educación Inclusiva. Algunas de ellas son coherentes con las prioridades y las prácticas que caracterizan la intervención de la UGOEP y su ET para apoyar al profesorado y las familias en esta difícil tarea de promover la inclusión. Consideremos este trabajo como el punto de partida a la Inclusión Educativa efectiva.

Palabras clave: orientación educativa, equipos técnicos, unidad general.

\section{Referencias}

Aguaded, C. (2010). Los equipos de orientación educativa en España. Huelva, Huelva: Artes Gráficas Bonanza, S.L.

Álvarez, M., \& Bisquerra, R. (2012). Orientación educativa. Modelos, áreas, estrategias y recursos. Madrid: Wolters Kluwer España, S.A.

Arroyo Almaraz, A., Castelo Moreno, A., \& Pueyo Caudevilla, M. (1994). El departamento de orientación: atención a la diversidad. Madrid: Narcea Ediciones.

Marchesi, A. y Martín, E. (1989). Reforma de la enseñanza, reforma del curricular. Madrid: Cuadernos de pedagogía, (168), 86-88.

Solé, I. y Martín, E. (2011). Un modelo educativo para la orientación y el asesoramiento. Barcelona: Graó. 